\section{CULTURA CIENTÍFICA PARA LOS CIUDADANOS Y CULTURA CIUDADANA PARA LOS CIENTÍFICOS}

\section{SCIENTIFIC CULTURE FOR CITIZENS \\ AND CIVIC CULTURE FOR SCIENTIFICS}

Mario Albornoz*

Resumen

¿Tiene la cultura científica una posición de primacía sobre la cultura ciudadana? ¿Cuánto necesita saber un ciudadano para poder tomar posición frente a las consecuencias del avance científico? Esas y otras preguntas similares son las que dan impulso a estas reflexiones acerca de cómo se relacionan entre sí los elementos cognitivos y valorativos de la cultura científica y cómo intersectan con la cuestión del poder, tanto en los escenarios de la política, como en los de la propia ciencia. Intentaré también señalar algunas limitaciones de la acción cultural entendida como alfabetización científica, en la formación de una conciencia ciudadana.

Palabras clave: difusión de la ciencia, apropiación de la ciencia, periodismo científico, cultura ciudadana, cultura científica.

Recibido: 6 de mayo de 2014. Aceptado: 5 de septiembre 2014

*Investigador principal del CONICET, Coordinador del Observatorio de la Ciencia, la Tecnología y la Sociedad, de la OEI, e investigador del Centro REDES (Argentina). E-mail: albornoz@ricyt.org , centroredes@ centroredes.org.ar

**Estas reflexiones fueron presentadas en el Seminario Internacional sobre Indicadores de Cultura Científica realizado en la Universidad de Salamanca en noviembre de 2013.
Summary

Has the scientific culture a position of primacy over civic culture? How much does a citizen need to know to take a position against the consequences of scientific progress? These and other questions are what give motivation to these reflections about how interrelated cognitive and evaluative elements of scientific culture and how it intersected with the question of power, both political scenarios, such as of science properly. I also will try to point out some limitations of cultural action understood as scientific literacy, in the formation of a civic consciousness.

Keywords: diffusion of science, appropriation of science, science journalism, civic culture, scientific culture.

Received: May 6, 2014. Accepted: Mayor 15, 2014
*Principal investigator of CONICET, Coordinator of the Science, Technology and Society, IEO, and researcher at the Center REDES (Argentina). E-mail: albornoz@ricyt.org, centroredes@centroredes.org. ar. WEB: www.centroredes.org.ar

**These reflections were presented at the International Seminar about Indicators of Scientific Culture at the University of Salamanca in November 2013. 


\section{INTRODUCCIÓN}

La ciencia es esencialmente comunicable. Se trata de una condición necesaria para la certificación de los conocimientos, su acumulación, el aprendizaje y la difusión de sus resultados. Lo sabía bien Robert Merton (1977), quien incluía la comunicabilidad como parte integrante del ethos del científico. Lo sabía también Michael Polanyi (1962), cuando argumentaba que la dinámica de la ciencia se apoya en los conocimientos adquiridos por los colegas y en tal aprendizaje, basado en los resultados obtenidos por unos y otros, se logra el avance de la ciencia.

En los orígenes de la ciencia moderna, que la comunicabilidad es una condición necesaria para el avance de la ciencia, era algo ya sabido en el siglo XVII por quienes conformaban el "colegio invisible", según expresión de Robert Boyle, en la etapa previa a la creación de la Royal Society. Es esta convicción acerca de la esencial comunicabilidad de la práctica científica, lo que justificó la inmediata creación de las Philosophical Transactions, en 1665 por parte de la Royal Society "para dar cuenta de los actuales emprendimientos, estudios y trabajos de los ingeniosos en muchas partes considerables del mundo". En forma casi simultánea, la Académie de Paris creaba el Journal des Savans con propósitos similares.

\section{1. ¿COMUNICACIÓN O TRADUCCIÓN?}

La comunicación del conocimiento científico, así entendida, ha sido pensada en gran medida como parte de un diálogo entre colegas, como el lenguaje básico de la "república de la ciencia". Algo diferente ocurre con la comunicación al público no especializado. La preocupación por comunicar los conocimientos científicos a los legos, reconoce distintos orígenes o fundamentos. Por un lado, se corresponde con la necesidad, por parte de los no especialistas, de conocer los avances de la ciencia. Por otro lado, en la cultura universitaria, tiene tradición la "extensión" del conocimiento a la sociedad, como una de las tres funciones básicas de las universidades, complementaria de las de docencia y de investigación.

Pero la preocupación "fuerte" por brindar información a la sociedad es más contemporánea y probablemente sea asociable a los movimientos favorables a un control social de la ciencia, luego de que la segunda guerra mundial permitiera el descubrimiento azorado del poder de la ciencia, representado icónicamente por la explosión nuclear.

También es asociable a los movimientos de protesta de los años sesenta. Siguiendo esta huella, a partir de entonces han irrumpido en escena movimientos estudiantiles, feministas, pacifistas y ecologistas que presionan para reorientar la investigación hacia fines civiles y reclaman una mayor transparencia y apertura a la participación pública en las decisiones del área. En alguna medida, estas protestas han tenido efecto, tanto en la conciencia ciudadana como en los propios gobiernos, que han debido atender algunas demandas de procedimientos democráticos y de transparencia pública en la orientación del rumbo de la investigación científica.

La comunicación institucional de la ciencia y de la tecnología se convirtió en una práctica normal y la figura del comunicador científico adquirió perfiles profesionales.

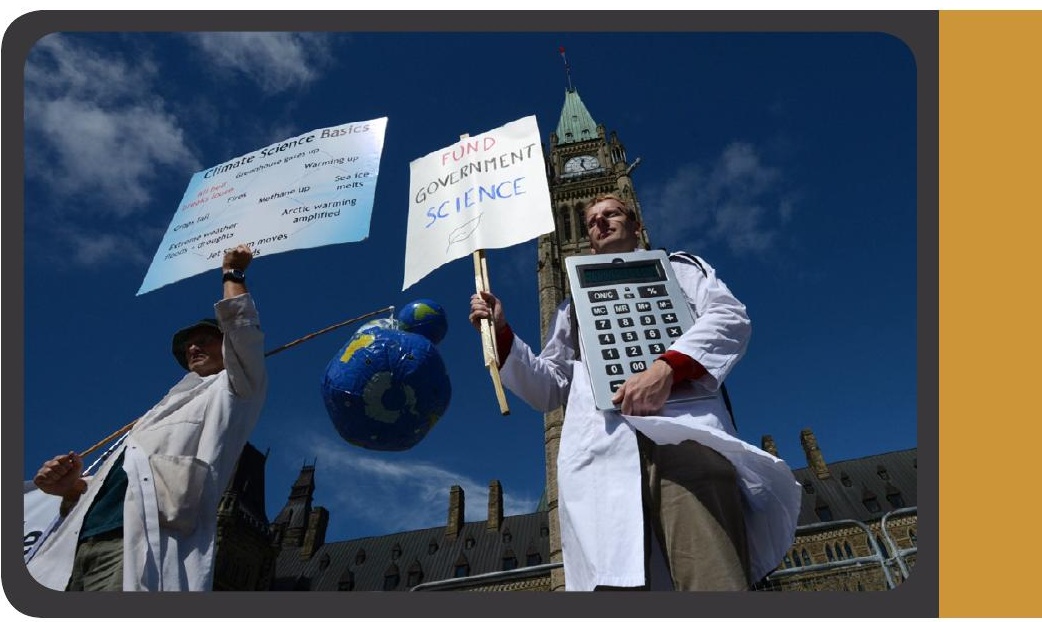

Algunos autores han señalado una paradoja en todo este proceso y es que al mismo tiempo que la ciencia fue aumentando su importancia como dinamizadora de la economía -la economía del conocimiento es fruto de tiempos recientes- esto produjo algunos efectos contrarios a la transparencia reclamada, ya que favoreció el secreto y la apropiación del conocimiento por parte de empresas.

Se ha señalado que en la comunicación del conocimiento científico a los legos, hay un problema de "traducción" de un lenguaje a otro. Cuando la comunicación con la sociedad es vista de este modo, como un problema de "traducción" entre dos lenguajes, se ponen en evidencia dos tipos de tensiones:

- La tensión de lograr que la sociedad esté preparada para comprender en alguna medida el lenguaje de la ciencia, aún traducido.

- La tensión de que la ciencia sea capaz de volcar sus conceptos, teorías y hallazgos en los moldes del lenguaje corriente.

La primera tensión conduce al intento de "alfabetizar" a la sociedad y concibe la comunicación científica bajo la perspectiva de lo que ha sido llamado como "modelo de déficit", esto es, el déficit de conocimiento científico de la sociedad. En este modelo, la comunicación científica está dirigida a superar el analfabetismo científico (Cortassa, 2012). La segunda tensión conduce a que la ciencia pueda o sea traducida a un lenguaje comprensible por el público, lo cual conduce a un dilema ya trillado acerca de quién es el mejor traductor: el científico con dotes de comunicador o el comunicador capaz de entender el lenguaje de la ciencia.

Ambas tensiones coinciden, sin embargo, en el propósito de facilitar la "compresión pública de la ciencia", se trata de brindar al ciudadano conocimientos para que tenga una actitud activa ante el avance de la ciencia y pueda tomar posición en ciertos temas con algún grado de conflictividad. Pero ¿qué es lo que el ciudadano debe comprender y para qué necesitaría hacerlo? La respuesta debería estar en el concepto de "cultura científica" entre cuyos componentes hay conocimientos, valores y representaciones.

La idea de una cultura científica identificada con la alfabetización científica podría no tomar en cuenta en forma suficiente la dimensión valorativa. En algún punto, esto es necesariamente así, porque quienes valoran son los ciudadanos y estos, en la medida que tengan capacidad crítica, tratarán de discriminar 
si en la transmisión de los conocimientos hay valores "embebidos" (encerrados dentro de ellos).

\section{CULTURA CIENTÍFICA}

Es difícil establecer un origen cierto de la expresión cultura científica. Quizás fuera en 1959 cuando Charles Percy Snow (1988), pronunció su conferencia en Cambridge sobre Las dos culturas. Es verdad, sin embargo, que a partir de la llustración, la ciencia y la cultura ya aparecían unidas en el concepto de "civilización", un término que a su vez está relacionado con la idea de progreso.

Se ha escrito mucho acerca de que la idea de progreso no es neutral y eso aplica al conocimiento científico. Tampoco lo es la ciencia, en la medida que se le utilice ideológicamente. Como en todo emprendimiento humano, la ciencia refleja intereses, espíritu corporativo y tendencias expansivas, más allá de sus fronteras. La racionalidad científica también trata de trascender sus fronteras e ir más allá de la propia ciencia. Trasladada al ámbito del pensamiento político, la racionalidad científica ha sostenido en gran medida el andamiaje fundacional de los estados modernos. La "civilización" ilustrada, es un proceso que implica el perfeccionamiento progresivo del conocimiento y, al mismo tiempo, de las leyes, la organización social y las formas de gobierno.

Obviando una definición general de cultura que pudiera llevarnos por otros derroteros que los que me he propuesto para estas reflexiones, señalaré - como ya lo anticipara- que una cultura ciudadana contiene, al menos, información, valores (o valoraciones) y representaciones sociales. Una cultura científica, por lo tanto, debería tener tales componentes, aunque referidos a la ciencia y la tecnología.

El modelo que sustenta el proyecto aquí presentado [1] distingue entre contenidos:

- Intrínsecos, a los que describe como propios de los procesos de alfabetización científica y de educación científica tradicional.

- Contenidos extrínsecos, tales como las representaciones sociales, actitudes y valoraciones acerca de la ciencia y la tecnología.

Los valores asociados a la idea del progreso están en el origen de aquellas representaciones de la ciencia como benefactora. Pero no son los únicos valores posibles. Después de la guerra, la cultura fue evolucionando desde la confianza ciega en la ciencia, hacia las sospechas y temores. Al fin y al cabo, la ciencia (o más bien la tecnociencia) es hija de la guerra.

Otro tipo de valores están asociados a la legitimación de la inversión necesaria. El costo de la "big science" reclama inversiones cuantiosas que los estados y las empresas están dispuestos a realizar en la medida de la satisfacción de sus intereses estratégicos, militares y económicos. El utilitarismo es uno de los rasgos de la cultura científica contemporánea.

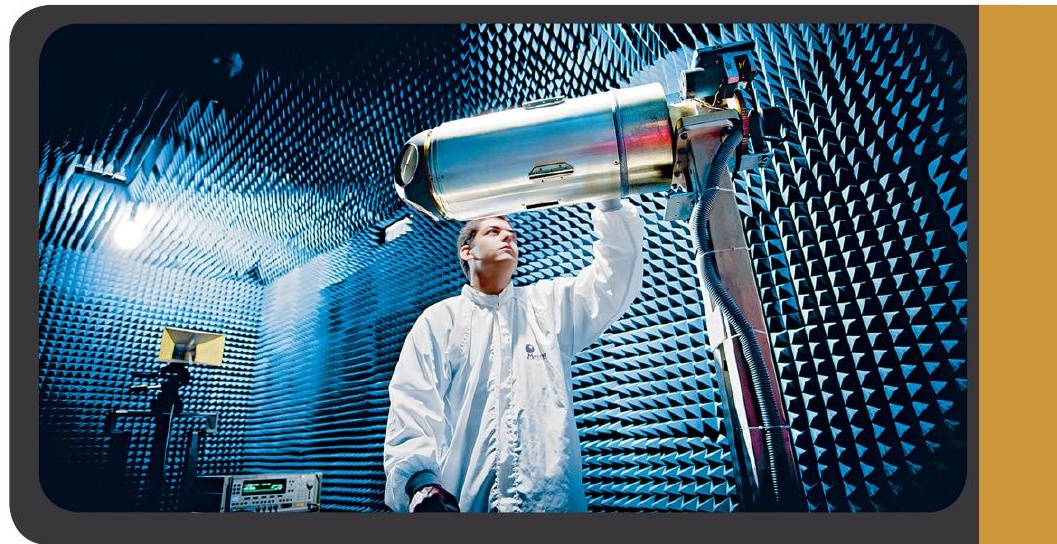

A la luz de la diversidad de valores, podríamos afirmar que no hay una cultura científica, sino diversas culturas científicas. Por lo menos podríamos identificar:

- Una cultura a la que podríamos llamar de matriz "Baconiana", centrada en el dominio utilitario de la naturaleza.

- Una cultura de matriz "Aristotélica" o "Platónica", centrada en el deseo desinteresado de conocer. Seguramente, a ella se refería Merton en su descripción del ethos del científico.

También hay quienes identifican una "tecno-cultura" surgida como resultado del aporte que la revolución de las tecnologías de base científica, realiza a la conformación de la cultura científica actual. La incesante avalancha de innovaciones tecnocientíficas da impulso a una configuración global de las culturas (Medina, 2001).

En una sociedad democrática y participativa, la consolidación de una cultura científica parece ser una condición necesaria para controlar riesgos, utilizar responsablemente los resultados e impulsar la innovación en las actividades productivas, públicas y privadas. Todo ello requiere información por parte de los ciudadanos. Por otro lado, una cultura científica de signo positivo parece ser también una condición necesaria para que sea posible sostener el apoyo público a la investigación científica y tecnológica, legitimando así la asignación de recursos crecientes a tales actividades.

En ambos sentidos, la cultura científica es manipulable, tanto para legitimar socialmente la inversión pública en ciencia y tecnología, como para alimentar algunos temores sobre riesgos, muchas veces legítimos, pero no siempre racionales y no siempre desinteresados. Por ello, una cultura científica de por sí no garantiza que los ciudadanos estén en condiciones de defender libremente sus derechos y sus deberes con relación a la ciencia y a la tecnología. Es el momento de preguntarnos qué es lo que deben saber para que ello sea posible.

\section{UNA RELACIÓN ASIMÉTRICA}

Hay una cuestión adicional, y es relativa a la relación de la ciencia con el poder. Theodor Roszak (1968), quien quedará en la historia como autor de la expresión "contracultura", criticaba la cultura científica por su deriva hacia la tecnocracia y el cientificismo. Ese riesgo había sido ya advertido por Juan Negrín, quien además de haber sido Primer Ministro de la República Española, era catedrático e investigador en fisiología. 
En 1942, estando exiliado en Inglaterra, Negrín participó en la reunión de la Asociación Británica para el Progreso de la Ciencia. Su intervención constituyó un alegato contra un enemigo que acecha al concepto ideal de democracia: la tecnocracia.

"El espíritu con el que informo estas consideraciones no sustenta, ya sea abierta o veladamente, un régimen de 'tecnocracia' o, más aún, de 'sofocracia'. La ciencia y la tecnología deben proveer lo necesario para un gobierno racional, pero de ningún modo pueden reemplazarlo". (British Association, 1942).

En su libro de 1968 "El nacimiento de la contracultura”, Roszak afirmaba que:

"El principal interés de quienes financian la I+D seguirá polarizado hacia el armamento, las técnicas control social, la manipulación del mercado y la manipulación del proceso democrático a través de la información y el consenso prefabricado".

Esta cita ha sido también recogida por José Antonio López Cerezo y José Sánchez Ron (2001) en un texto sobre ciencia, tecnología, sociedad y cultura en el cambio de siglo, en el que hacen mención al "síndrome de Frankenstein" (el monstruo que hemos creado).

La idea de que la ciencia es un continente aislado que debe ser vinculado mediante puentes comunicativos con la sociedad, no ha sido así siempre. En cambio, la idea de que la ciencia debe gobernar sí es antigua, y más de una vez ha sido imaginada así, como cláusula constitutiva de la relación entre la ciencia y la sociedad, para que esta pueda ser beneficiada por las aplicaciones de los conocimientos adquiridos.

En su fantástico relato de la "Nueva Atlántida", Francis Bacon (1991) narra la peripecia de unos navegantes que viniendo hacia Europa desde el Perú, quedaron atrapados por una tempestad. "Nos dimos porperdidos y nos preparamos para la muerte", pone Bacon en boca del relator. Sin embargo, la tormenta cedió y los navegantes recalaron en un buen fondeadero que era el puerto de una bella ciudad "bien construida $y$ que ofrecía un agradable panorama".

Pronto habrían de saber que habían llegado al reino de Ben Salem, una sociedad organizada de acuerdo con la racionalidad científica, bajo la conducción de una cofradía de sabios: la Casa de Salomón, cuyo fin era:

"el conocimiento de las causas y de los movimientos ocultos de las cosas y el engrandecimiento de los límites del imperio humano, para efectuar todas las cosas posibles".

Y las cosas posibles eran sorprendentes:

- tenemos profundas cavernas que usamos para coagulaciones, endurecimientos, refrigeraciones y conservación de cuerpos;

- producimos nuevos metales artificiales y otros materiales;

- tenemos diversos cementos, como la porcelana de los chinos, pero en mayor variedad;

- tenemos grandes estanques de donde obtenemos agua dulce del agua salada;
- tenemos diversas cámaras en las que modificamos el aire;

- ensayamos toda clase de inoculación e injertos de árboles frutales;

- tenemos medios para hacer crecer diversas plantas sin semillas;

- tenemos aguas que maduramos para que se vuelvan nutritivas;

- tenemos tiendas de medicinas con mayor variedad que en Europa;

- tenemos artes mecánicas y gran variedad de hornos, cámaras de perspectiva en las que hacemos demostraciones de todas las luces $y$ radiaciones, así como multiplicadores de la luz;

- tenemos fábricas de máquinas e instrumentos para toda suerte de movimientos...

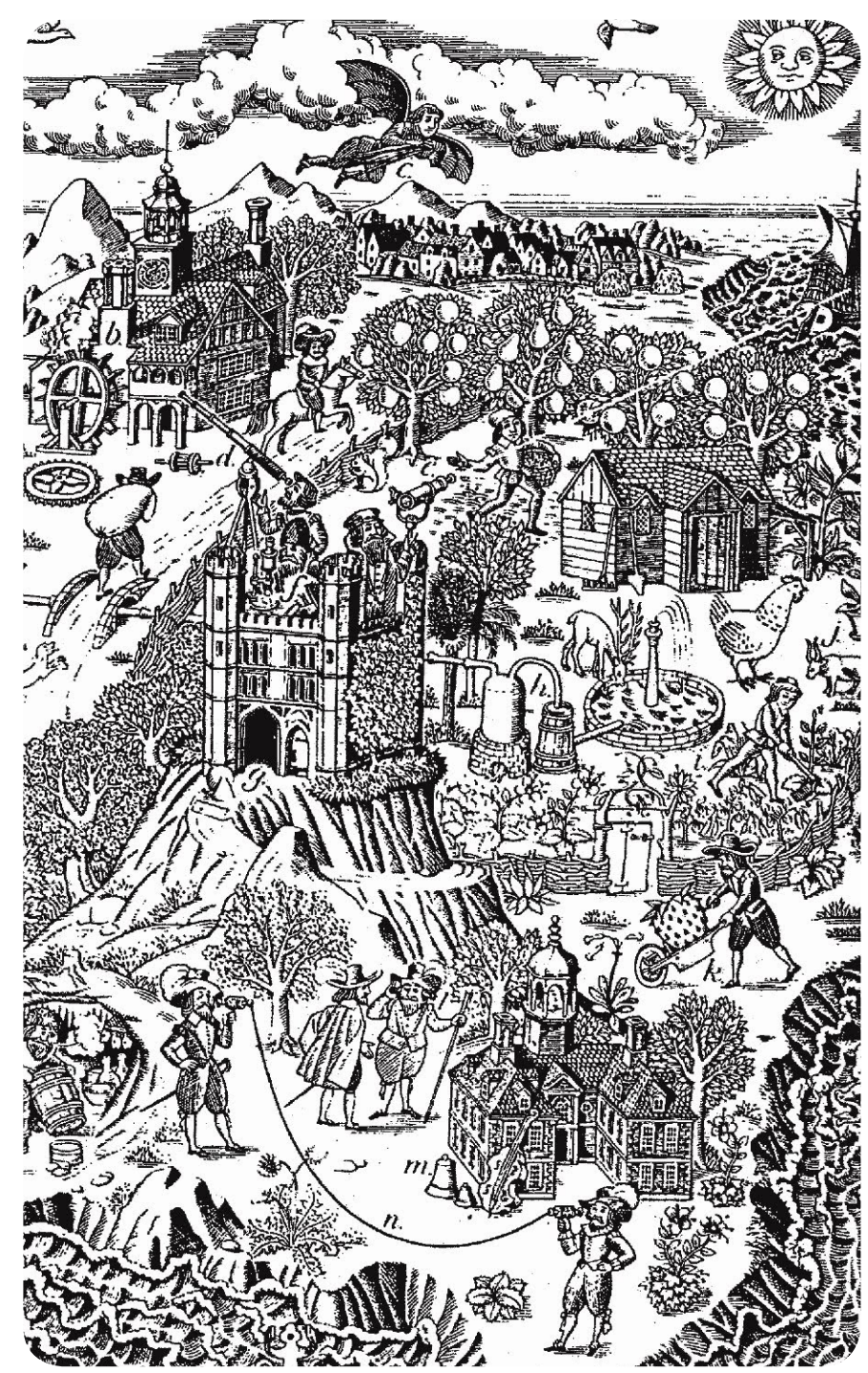

Tenían, además, ciudadanos satisfechos con este orden. La ciudadanía en aquella isla se basaba en el reconocimiento de la primacía de los científicos.

Un detalle importante del relato del sabio de la Casa de Salomón explicitaba la asimetría básica de la relación. Es sus palabras, refiriéndose a los conciliábulos de aquel cenáculo de sabios, afirmaba:

\footnotetext{
"También nos consultamos cuáles de los inventos yexperimentos que hemos descubierto deben publicarse y cuáles no; y hacemos todos juramento de secreto para ocultar aquellos que pensamos conveniente mantener en secreto, aunque algunos de ellos los revelamos a veces al Estado, y algunos no".
}

Este texto contradice el carácter de necesaria comunicabilidad y universalidad de los conocimientos, ya que otorga a los sabios el poder revelar o no los 
secretos, no solamente a la población, sino también al Estado. Tomando esto al pie de la letra, la "Casa de Salomón" estaba por encima de todos, incluso por sobre el propio Estado.

\section{LA CULTURA CIENTÍFICA Y LA PARTICIPACIÓN} CIUDADANA

¿Es aplicable la metáfora del Reino de Ben Salem a la problemática de la cultura científica y la participación ciudadana contemporáneas? No puede ser, obviamente, trasladable en forma directa.

Sin embargo, desde algún punto de vista, la difusión social de la cultura científica puede repetir el mismo tipo de efecto: que la sociedad se organice en torno a los valores de la ciencia, la que vería garantizada, de tal modo, su posición de primacía. En este sentido, algunas facetas de la difusión de la cultura científica podrían ser consideradas como la preservación de su propio mito.

Hay una faceta, sin dudas positiva, que es la de brindar a los ciudadanos información acerca de los riesgos derivados de los avances de la ciencia y la tecnología, así como de las posibles alternativas. Pero hace algún ruido la identificación (aunque sea parcial) de la cultura científica con la alfabetización científica. Es necesario justificar cómo y de qué manera la alfabetización científica conduciría a la toma de conciencia y a la actuación ciudadana participativa.

Es indudable que para que los ciudadanos puedan manifestarse deben estar informados, pero cuando lo son, ¿en qué medida son informados acerca del contenido científico de los problemas y en qué medida acerca del contenido político?

La discusión sobre temas complejos de respeto al ambiente, a la utilización responsable de los recursos naturales, a la contaminación, al modelo energético basado en los hidrocarburos, al agua, a las convicciones religiosas y a dilemas morales, entre otros, requiere información y demanda conocimiento experto, es verdad, pero lo que se discute no es sobre el contenido científico o técnico, sino sobre las consecuencias sociales, económicas y políticas, entre otras dimensiones.

\section{PENSAR Y CONOCER}

¿Cuánto debe saber el ciudadano para poder tomar posición? Me resulta útil para reflexionar sobre ello recordar a Hannah Arendt, quien era muy crítica con la idea moderna de que el pensamiento sirve a la ciencia empírica. Más bien, distinguía entre conocer y pensar. El conocimiento pertenece al ámbito de la ciencia. El pensar, en cambio, tiene que ver con la verdad. El conocimiento genera información. El pensamiento, en cambio, conduce a la responsabilidad personal.

El conocimiento es, con toda seguridad, necesario y de allí la importancia de la educación, ya que en el proceso educativo se adquiere una formación básica en ciencias exactas y en ciencias sociales; además, se aprende a pensar. La base educativa de una sociedad es la base de su cultura científica y ciudadana.
Pero la información adaptada al lenguaje de los legos no los convierte en científicos y por lo tanto cabe preguntarse en qué medida ello los habilita para participar en la propia construcción cognitiva, ya que serán los propios científicos los que conservarán el poder de determinar qué conocimientos se comunican y cuáles no. Es verdad que hoy, es una idea frecuente la de que el conocimiento se construye a partir de problemas en cuya elaboración participan diversos actores. Pero en el límite, lo que conduce a la conciencia ciudadana es la capacidad de pensar, no el conocimiento de las explicaciones científicas.

El pensamiento es condición básica de la ciudadanía. Es lo que constituye al ciudadano. El pensamiento está vinculado con la verdad y en este sentido el pensamiento conduce a enfrentar los riesgos porque el propio pensamiento es riesgoso. El pensamiento es de naturaleza moral y conduce necesariamente a confrontar con el mal.

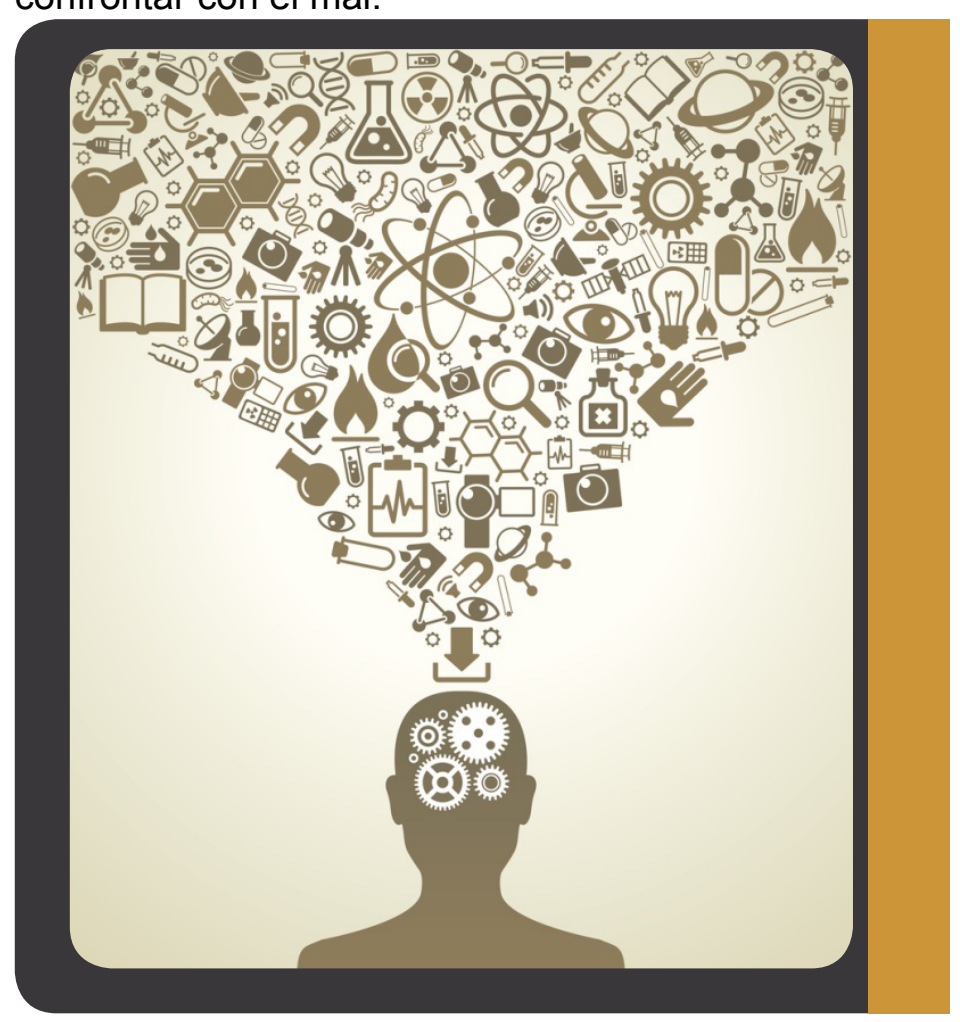

\section{CULTURA CIUDADANA}

La garantía de que la cultura científica no sirva como manipulación política, de mercados o de convicciones morales, no puede provenir de la propia ciencia sino exclusivamente de la ciudadanía. Dicho de otro modo, es necesario reconciliar el conocimiento con el pensamiento.

El verdadero puente entre la ciencia y la sociedad, se construye en la medida que los científicos asumen la cultura ciudadana, más que en la medida que los ciudadanos asuman la cultura científica. Esto es, cuando dejan de lado la pretensión de superioridad, cuando rompen la insularidad y cuando su actividad se orienta en función de valores profundamente humanos. Esto implica opciones y elecciones cotidianas.

Michael Polanyi argumentaba en varios de sus textos que su buen amigo Bukharin, investigador científico soviético en tiempos de Stalin, se asombraba por las discusiones de la comunidad científica inglesa acerca de la utilidad social de los conocimientos, y afirmaba que esos dilemas no existían en la URSS, porque la distinción entre interés científico e interés social, no existía. Más allá de que esta anécdota 
invariablemente concluía en que su amigo fue fusilado por el estalinismo poco tiempo después, lo cual demostraba a la vez su ingenuidad elemental y lo perverso del régimen, el relato pone en evidencia que el sistema impedía pensar y aliviaba la conciencia moral de quien no tenía que tomar decisiones porque el Estado las había tomado por él.

La cultura ciudadana exige pensar y asumir valores propios de un colectivo social más amplio que la comunidad científica. Esto implica escuchar a la sociedad, como parte de ella, y tomar decisiones que tengan en cuenta los contextos locales concretos

\section{Una mirada desde lberoamérica}

La idea de que solo un ciudadano alfabetizado científicamente puede participar en la toma de decisiones con respecto a las consecuencias del avance de la ciencia y la tecnología, es por lo menos exagerada y probablemente una distorsión.

Desde la perspectiva latinoamericana esta idea choca contra la diversidad cultural y contra una maraña de intereses económicos y políticos.

En muchos conflictos ambientales en América Latina, la racionalidad científica alfabetizada se pone del lado de grandes empresas que explotan recursos naturales sin tomar todos los recaudos necesarios para minimizar los impactos.

Muchas comunidades locales que resisten este tipo de explotación son menospreciadas por defectos de alfabetización científica. Sin embargo, la dignidad de estos actos de resistencia se sustenta en valores más vinculados con la vida, con el vínculo con la naturaleza, con la voluntad colectiva y con el pensamiento.

Para mayor complejidad, en varios conflictos vinculados con explotaciones mineras, con la preservación de glaciares, con plantas fabriles presuntamente contaminantes, con el uso de pesticidas, entre otros, los informes científicos frecuentemente arrojan resultados contradictorios, según quiénes los esgriman.

¿Cuánto deben saber los ciudadanos para defender sus posiciones en este tipo de conflicto? Probablemente no sea la alfabetización lo más decisivo, sino la capacidad de pensar críticamente.

En los países latinoamericanos, por último, se registra actualmente un consenso por parte de los gobiernos y de la opinión pública, acerca de que la ciencia, la tecnología y, en otro plano, la innovación, constituyen instrumentos que los países deben cuidar y aprender a utilizar para poder alcanzar un desarrollo sustentable. Hay conciencia de que la brecha entre ricos y pobres no es solo una brecha en la distribución de la riqueza, sino también del conocimiento. Revertir esta situación demanda que la agenda de la investigación científica y tecnológica sea construida desde los valores ciudadanos y no a imitación de la agenda de los países más avanzados. La ciencia es universal, pero las agendas no.

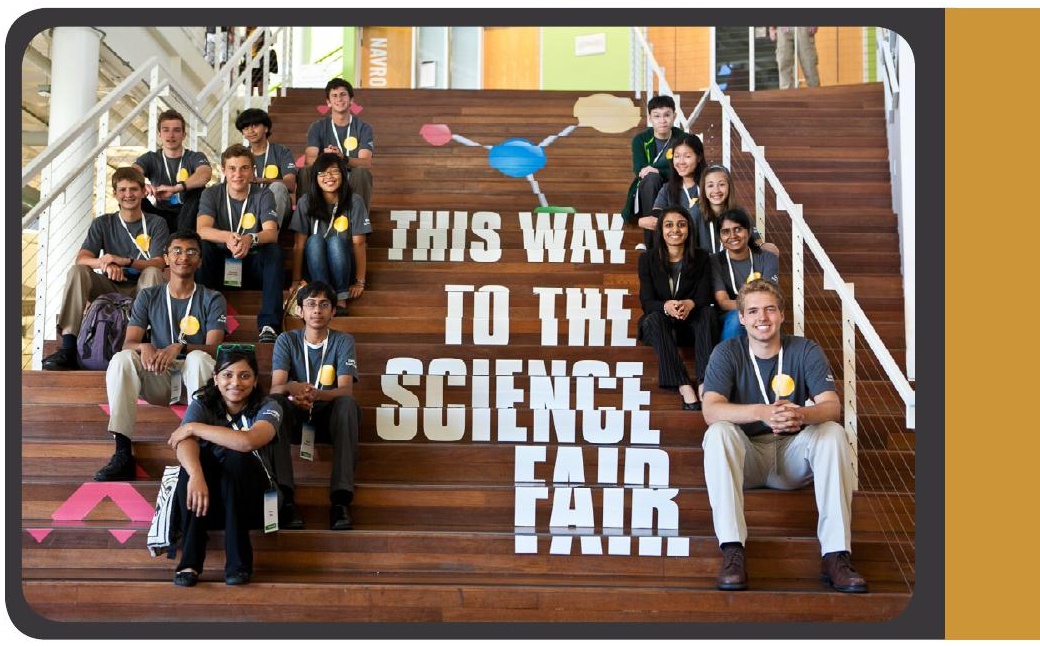

El éxito en el camino del desarrollo depende en buena medida de la capacidad de gestionar el cambio tecnológico y aplicarlo a la producción, la explotación racional de recursos naturales, la salud, la alimentación, la educación y la atención de otros requerimientos sociales. Esto implica conocimiento pero demanda sobre todo opciones ciudadanas.

Ningún país es autosuficiente en ciencia y tecnología. Por este motivo, la cultura científica debe ser solidaria y fértil en la conformación de redes y de trabajo colaborativo. Gestionar estas posibilidades con un sentido estratégico sobre la base de un profundo conocimiento de las necesidades locales sería el reflejo de una cultura que integre los valores científicos y los ciudadanos [2].

\section{BIBLIOGRAFÍA}

- ARENDT, Hannah (2002); La vida del Espíritu; Paidós, Buenos Aires.

- BACON, Francis (1991); Nueva Atlántida; Editoria Porrúa, México.

- BRITISH ASSOCIATION FOR ADVANCEMENT OF SCIENCE, (1942), 'El Adelanto de la Ciencia en Relación con el Progreso Mundial', en: El Progreso de la Ciencia, Asociación Argentina para el Progreso de la Ciencia, Buenos Aires.

- CORTASSA, Carina (2012); La ciencia ante el público; EUDEBA, Buenos Aires.

- LÓPEZ CEREZO, José Antonio y SÁNCHEZ RON, Manuel (2001), Ciencia, tecnología, sociedad y cultura en el cambio de siglo; Biblioteca Nueva - OEI, Madrid.

- MEDINA, Manuel (2001); 'Ciencia y tecnología como sistemas culturales' en López Cerezo y Sánchez Ron: Ciencia, tecnología, sociedad y cultura en el cambio de siglo; Biblioteca Nueva OEI, Madrid.

- MERTON, Robert (1977); La Sociología de la ciencia; Alianza Editorial, Madrid.

- POLANYI, Michael (1962); The Republic of Science; Minerva 1:54-74, Kluwer Academic Publishers.

- POLANYI, Michael (1983); The tacit dimension; Peter Smith, Gloucester Mass.

- ROSZAK, Theodore (1968); El nacimiento de una contracultura; Kairós, Barcelona. 
- SNOW, Charles P. (1988); Las dos culturas; Nueva Visión, Buenos A.

\section{NOTAS}

[1] El Proyecto Indicadores de Cultura Científica y Tecnológica fue desarrollado por el Instituto de Estudios de la Ciencia y la Tecnología, de la Universidad de Salamanca, bajo la Dirección de Miguel Ángel Quintanilla.

[2] Documento de Trabajo No: 44. Fecha: noviembre de 2013. ISSN 2313 - 9811. Autorizado para su publicación en la Revista Luciérnaga-Comunicación N11. Disponible en www.centroredes.org.ar

\section{Para citar este artículo:}

Albornoz, Mario (2014). Cultura Científica para los Ciudadanos y Cultura Ciudadana para los

Científicos. Revista Luciérnaga, Año 6, N11. Facultad de Comunicación Audiovisual- Politécnico Colombiano Jaime Isaza Cadavid-PCJIC. Colombia \& Escuela de Ciencias de la Comunicación - Universidad Autónoma de San Luis PosotosíUASLP. México. ISSN 2027- 1557. Págs. 71-77.

DOI:10.33571/revistaluciernaga.v6n11a3 